\title{
Healthcare beliefs, health information seeking, and healthcare setting preferences among women who inject drugs by community supervision status
}

\author{
Ariel Hoadley ${ }^{1,2^{*}}$ D, Sarah Bauerle Bass ${ }^{1,2}$, Jesse Brujaha ${ }^{2}$, Paul A. D'Avanzo ${ }^{1,2}$ and Patrick J. Kelly ${ }^{2}$
}

\begin{abstract}
Objective: Women on community supervision who inject drugs have significant unmet healthcare needs. However, it remains unclear how the intersection of community supervision and injection drug use influences healthcare experiences and service setting preferences. The present study examines whether the intersection of community supervision and injection drug use is associated with differences in women's healthcare beliefs, healthcare experiences, and service setting preferences.
\end{abstract}

Methods: A secondary analysis was conducted on a previously collected sample of women who inject drugs recruited from a syringe exchange and social service organization for a cross-sectional survey. Participants $(N=64)$ were mostly White (75\%), and more than a quarter were currently on probation or parole (26\%).

Results: Independent samples $t$-tests and chi-square tests revealed no significant differences on sociodemographic variables by community supervision status. There were no significant differences by community supervision status across seven indicators of healthcare confidence ( $p s>.05$ ). However, results revealed significant differences in past experiences and beliefs about healthcare, health information seeking, and healthcare setting preferences by community supervision status ( $p s<.05$ ), where women on community supervision less frequently sought health information and medical care outside of emergency departments.

Conclusions: Findings provide preliminary evidence about differences in the healthcare experiences and setting preferences of women who inject drugs on community supervision.

Keywords: Community supervision, Patient preference, Health information seeking, Injection drug use, Healthcare setting

Community supervision, defined as being on probation or parole, is significantly associated with greater physical, mental health, and substance use healthcare needs (Dong, Must, Tang, Beckwith, \& Stopka, 2018). Yet this

\footnotetext{
* Correspondence: ariel.hoadley@temple.edu

'Department of Social and Behavioral Sciences, Temple University College of Public Health, 1301 Cecil B. Moore Ave., Ninth Floor, Philadelphia, PA 19122, USA

${ }^{2}$ Risk Communication Laboratory, Temple University College of Public Health, 1301 Cecil B. Moore Ave., Ninth Floor, Philadelphia, PA 19122, USA
}

population is less likely to use outpatient healthcare services than other adults (Hawks et al., 2020). While legislation, such as the Affordable Care Act, has been enacted to increase insurance coverage among individuals recently released from incarceration or who are on community supervision (Bandara et al., 2015; Cuellar \& Cheema, 2012; Knapp et al., 2019), improved insurance coverage has not sufficiently addressed gaps in outpatient service utilization rates among justice-involved

C C The Author(s). 2021 Open Access This article is licensed under a Creative Commons Attribution 4.0 International License, which permits use, sharing, adaptation, distribution and reproduction in any medium or format, as long as you give appropriate credit to the original author(s) and the source, provide a link to the Creative Commons licence, and indicate if changes were made. The images or other third party material in this article are included in the article's Creative Commons licence, unless indicated otherwise in a credit line to the material. If material is not included in the article's Creative Commons licence and your intended use is not permitted by statutory regulation or exceeds the permitted use, you will need to obtain permission directly from the copyright holder. To view a copy of this licence, visit http://creativecommons.org/licenses/by/4.0/. The Creative Commons Public Domain Dedication waiver (http://creativecommons.org/publicdomain/zero/1.0/) applies to the data made available in this article, unless otherwise stated in a credit line to the data. 
individuals who have re-entered into the community and among the broader population of individuals on community supervision (Hawks et al., 2020; Saloner, Bandara, McGinty, \& Barry, 2016). The continued underutilization of outpatient care among Medicaid enrollees has highlighted additional barriers to service use, such as perceived lack of coverage or unaffordable care, undervaluing primary care, length of time to first available appointment, and transportation (Saluja et al., 2019).

While the proportion of US adults under community supervision has steadily declined for a decade since 2008, Pennsylvania continues to exceed the national average by $64 \%$ as of 2018 (Kaeble \& Alper, 2020). In Philadelphia, women experience disproportionately worse health outcomes after release from prison than men, including those on community supervision. In an analysis of Philadelphia state prison releases from 2010 to 2016, researchers found that women experienced significantly higher rates of all-cause and overdose-specific mortality after release compared to both their male counterparts and non-incarcerated adults (Pizzicato, Drake, Domer-Shank, Johnson, \& Viner, 2018). Women who had been on probation or parole in the past year also have significantly greater odds of injection drug use compared to women with no justice involvement, even after controlling for housing stability (Lorvick, Comfort, Krebs, \& Kral, 2015). Thus, the cross-section of women who are both justice-involved and who inject drugs is an important group of focus.

One way of explaining gender disparities in health outcomes and healthcare utilization rates among community supervised populations is through the lens of cumulative disadvantage. Women on community supervision experience multiple levels of adverse circumstances and opportunity gaps that coalesce into significant, cumulative social disadvantages relative to men (Bohmert \& DeMaris, 2018), such as having significantly greater risk of experiencing intimate partner violence, having co-occurring mental health disorders, being unable to find employment, and having a history of trauma (Salem, Nyamathi, Idemundia, Slaughter, \& Ames, 2013). Programs for women with co-occurring trauma and substance use disorders, such as integrated cognitive behavioral therapy programs implemented within carceral facilities (Zlotnick, Najavits, Rohsenow, \& Johnson, 2003) and community settings (Hien et al., 2020), address the complex traumas experienced by justice-involved women with substance use disorders. The effectiveness of these integrated cognitive behavioral programs aligns with a recent meta-analysis that found preliminary evidence favoring integrated cognitive behavioral interventions for addressing co-occurring mental health and substance use over single-disorder interventions, such as interventions focused solely on either substance use or mental health (Mehta et al., 2021).

Stigma also explains gender disparities in healthcare experienced by women on community supervision, particularly among women who inject drugs (WWID). Stigma impacts healthcare access and utilization among women from socially marginalized groups, including justice-involved women (Salem et al., 2013; van Olphen, Eliason, Freudenberg, \& Barnes, 2009) or who use alcohol and other drugs (Fraser, Moore, Farrugia, Edwards, \& Madden, 2020; van Olphen et al., 2009). Among people who inject drugs (PWID), stigma adversely affects the patient-provider relationship and healthcare utilization through repeated processes of mistreatment and anticipation of subsequent mistreatment by providers and office staff (Biancarelli et al., 2019).

Given that women on community supervision and WWID have significant unmet health needs (Dion et al., 2020; Hawks et al., 2020) and experience significant social vulnerability (Lorvick et al., 2015), understanding how the combined experiences of community supervision and injection drug use influence women's healthcare experiences and service setting preferences can inform how best to intervene with this population. To identify routes for addressing unmet healthcare needs, the present study examined how beliefs about healthcare, health information seeking behaviors, and healthcare setting preferences varied by community supervision status among a sample of WWID in Philadelphia.

\section{Methods \\ Design}

The study is a secondary analysis of a previously collected, cross-sectional survey that was conducted among a sample of one hundred women at risk for HIV who were actively utilizing a syringe exchange program in Philadelphia. The purpose of the original study was to develop targeted communication about pre-exposure prophylaxis (PrEP) for an intervention to promote uptake and adherence among WWID. The study was reviewed and approved by the Temple University Institutional Review Board, and all participants provided informed consent.

\section{Sample}

Women were recruited from a syringe exchange and social service organization that provides services to people with substance use disorder in Philadelphia. Inclusion criteria included being self-reported female and at risk for HIV. Only those who reported current use of injection drugs were used in this analysis. Eighty-nine percent of the 64 eligible women reported currently taking opioids. Most women were White (75\%), 9.4\% were Black 
or African American, 7.8\% were Hispanic or Latinx, and $7.8 \%$ identified as multiple races or another race. Women ranged in age from 23 to 54 years, with a mean age of 39 years $(s d=8.0)$. Health insurance was prevalent, with $86 \%$ reporting active coverage. Most women had completed high school or a GED (81\%); $25 \%$ reported completing a college degree. Almost all (97\%) had a history of incarceration.

\section{Measures}

\section{Individual characteristics}

Self-reported individual characteristics included age, race and ethnicity, housing stability, educational attainment, monthly income in dollars, incarceration history, and current use of opioids.

\section{Community supervision status}

The independent variable was community supervision status, which was self-reported and operationally defined as currently being on probation or parole.

\section{Healthcare confidence, healthcare beliefs, and health information seeking}

Dependent variables included healthcare confidence, healthcare beliefs, and health information seeking. Using selected items from an adapted version of the Patient Self Advocacy Scale (Brashers, Haas, \& Neidig, 1999), healthcare confidence was assessed with five questions and health information seeking was assessed with a single question. Healthcare beliefs were assessed with seven survey items developed from previous formative research. All items were assessed on a bipolar Likert scale, ranging from 0 to 10 . Items were dichotomized as agreements vs. neutral or disagreements. The cut-point for defining agreement was a score of a six or higher, and a neutral or disagreement included ratings of five or below.

\section{Healthcare access}

Two binary survey items assessed healthcare access: 1 ) current insurance status and, 2) whether distance from healthcare facilities was a barrier to healthcare.

\section{Healthcare setting preferences}

Participants selected all of the healthcare settings at which they would prefer to receive healthcare services, in the event that they needed to receive medical care for themselves. Respondents were also given an option for preferring not to receive care. A binary variable was computed to identify individuals who preferred to only visit the emergency room or to not receive care. The remaining respondents selected at least one outpatient-, clinic-, or other community organization-based setting for receiving care.

\section{Analysis}

Independent samples $t$-tests compared respondent mean age by community supervision status. Chi-square tests of independence identified significant differences in categorical individual characteristics and other study variables by community supervision status. If at least one cell had an expected count of fewer than five, significance was calculated using Fisher's exact, two-sided test. All data were analyzed in IBM SPSS for Mac, Version 26.0 .

\section{Results}

Independent samples $t$-tests and chi-square tests revealed no significant differences on any individual characteristics by community supervision status. Results are reported in Table 1.

Chi-squared tests revealed no significant differences in healthcare access by community supervision status ( $p \mathrm{~s}>$ $.05)$. There were also no significant differences by community supervision status across all seven indicators of healthcare confidence ( $p s>.05)$. However, significant differences in healthcare beliefs, health information seeking, and healthcare setting preferences emerged by community supervision status. For example, more WWID on community supervision reported that the emergency room was the easiest setting to receive medical care, $X^{2}(1, N=64)=6.705, p=.01$. Being on probation or parole was also associated with a preference for solely receiving care at only the emergency room or for receiving no medical care $X^{2}(1, N=64)=4.187, p<.05$. Finally, fewer WWID on community supervision reported actively seeking health information for themselves $X^{2}(1, N=64)=5.957, p<.05$. Results are reported in greater detail in Table 2.

\section{Discussion}

The current study presents preliminary evidence towards differences in specific healthcare experiences and preferences of women on community supervision who are actively using injection drugs. These results align with the current literature which cites social vulnerability (Lorvick et al., 2015) and cumulative social disadvantage (Bohmert \& DeMaris, 2018) as determinants of decreased healthcare utilization among WWID and women on community supervision.

The current study found that being on probation and parole was significantly associated with a sole preference for using the emergency room for care or for not receiving any care. A stated preference for the emergency department is noteworthy, given that using the emergency room for usual care is associated with worse patient care experiences, less receipt of high-value clinical care (Levine, Landon, \& Linder, 2019), and less continuity of care (Pourat, Davis, Chen, Vrungos, \& Kominski, 2015). 
Table 1 Characteristics of WWID by community supervision status $(N=64)$

\begin{tabular}{|c|c|c|c|c|c|c|}
\hline \multirow[b]{2}{*}{ Variable } & \multicolumn{2}{|c|}{ Not currently on probation or parole $(n=46)$} & \multicolumn{2}{|c|}{ Currently on probation or parole $(n=18)$} & \multirow[b]{2}{*}{$X^{2}$} & \multirow[b]{2}{*}{$p$} \\
\hline & $\%$ & $\mathrm{n}$ & $\%$ & $\bar{n}$ & & \\
\hline Age, in years, $M(s d)$ & 38.8 & (8.4) & 39.6 & (7.0) & $0.381^{\mathrm{a}}$ & 0.704 \\
\hline \multicolumn{7}{|l|}{ Race and ethnicity } \\
\hline White, non-Hispanic & $71.7 \%$ & 33 & $83.3 \%$ & 15 & 0.928 & $0.522^{b}$ \\
\hline Hispanic, Latinx, or not White & $28.3 \%$ & 13 & $16.7 \%$ & 3 & & \\
\hline \multicolumn{7}{|l|}{ Housing stability, past 6 months } \\
\hline Has been homeless & $91.3 \%$ & 42 & $77.8 \%$ & 14 & 2.164 & $0.206^{b}$ \\
\hline Has not been homeless & $8.7 \%$ & 4 & $22.2 \%$ & 4 & & \\
\hline \multicolumn{7}{|l|}{ Educational attainment } \\
\hline HS graduate, GED, or less & $58.7 \%$ & 27 & $44.4 \%$ & 8 & 1.060 & 0.303 \\
\hline At least some college & $41.3 \%$ & 19 & $55.6 \%$ & 10 & & \\
\hline \multicolumn{7}{|l|}{ Monthly income } \\
\hline Less than or equal to $\$ 500 /$ month & $23.9 \%$ & 11 & $38.9 \%$ & 7 & 1.435 & 0.354 \\
\hline Greater than $\$ 500 /$ month & $76.1 \%$ & 35 & $61.1 \%$ & 11 & & \\
\hline \multicolumn{7}{|l|}{ Incarceration history } \\
\hline Has been in jail or prison & $95.7 \%$ & 44 & $100.0 \%$ & 18 & 0.808 & $1.000^{\mathrm{b}}$ \\
\hline Never been in jail or prison & $4.3 \%$ & 2 & $0.0 \%$ & 0 & & \\
\hline \multicolumn{7}{|l|}{ Current opioid use } \\
\hline Yes & $84.8 \%$ & 39 & $100.0 \%$ & 18 & 3.076 & $0.177^{b}$ \\
\hline No & $15.2 \%$ & 7 & $0.0 \%$ & 0 & & \\
\hline
\end{tabular}

Notes. WWID Women who inject drugs, HS high school, $t$-test independent samples $t$-test, $X^{2}$ chi-square test

${ }^{\text {a }}$ Statistical significance was calculated using an independent samples $t$-test for age because it was a continuous variable

${ }^{\mathrm{b}}$ Statistical significance was calculated using Fisher's exact, two-sided test because at least one cell had an expected count of fewer than 5

$* p<.05$

Among PWID, mental health is the leading reason for emergency room visits (Dion et al., 2020), yet the emergency room mental health treatment is fraught with challenges that result in negative patient experiences, such as a lack of dignity, long wait times, and decreased autonomy (Thomas et al., 2018). Preference for emergency services may result from avoiding preventative and non-emergency medical care, strategies commonly used by PWID to limit exposure to the injection drug use stigma that remains prevalent in healthcare settings (Biancarelli et al., 2019). Primary care services may also be deprioritized by women on community supervision due to higher ranking daily needs, such as food and housing security (Dong et al., 2018), resulting in greater use of acute care services. In addition, a preference for emergency departments over other healthcare settings aligns with recent qualitative findings that Medicaid and public insurance enrollees described emergency departments and urgent care clinics as faster, cheaper, and more familiar than outpatient primary care settings (Saluja et al., 2019).

Finally, it is significant that these women were significantly less likely to search for health information for themselves. The intersectional stigma of being on community supervision, being female, and using injection drugs may result in higher stress and a less supportive social environment, which are factors associated with lower health literacy and patient engagement (McCormack, Thomas, Lewis, \& Rudd, 2017). Further investigation is needed into the specific barriers, including multilevel stigma, that inhibit active health information seeking and outpatient healthcare use by WWID on community supervision to better address their unmet health needs. The capacity for community corrections officers to improve and help foster their clients' active health information seeking and health literacy skills should also be explored.

Previous programs that have been implemented to increase outpatient and primary care use among individuals recently released from incarceration have included integrated and specialized primary care services for justice-involved individuals (Howell et al., 2021; Morse et al., 2017; Wang et al., 2019), patient navigation (e.g., Binswanger, Whitley, Haffey, Mueller, \& Min, 2015; O'Connell, Visher, \& Becker, 2020), and systems change interventions (O'Connell et al., 2020). In a study of women released from incarceration who were referred by community health workers to Transitions Clinic 
Table 2 Healthcare confidence, past experiences and beliefs about healthcare, healthcare access, health information seeking, and healthcare setting preferences by community supervision status among WWID (N=64)

\begin{tabular}{|c|c|c|c|c|c|c|}
\hline \multirow[b]{2}{*}{ Variable } & \multicolumn{2}{|c|}{$\begin{array}{l}\text { Not currently on probation or } \\
\text { parole }(n=46)\end{array}$} & \multicolumn{2}{|c|}{$\begin{array}{l}\text { Currently on probation or } \\
\text { parole }(n=18)\end{array}$} & \multirow[t]{2}{*}{$x^{2}$} & \multirow[t]{2}{*}{$p$} \\
\hline & $\%$ & $\mathrm{n}$ & $\%$ & $\mathrm{n}$ & & \\
\hline \multicolumn{7}{|l|}{ Healthcare confidence } \\
\hline Lack of confidence negatively affects healthcare & $21.7 \%$ & 10 & $44.4 \%$ & 8 & 3.299 & 0.069 \\
\hline Feels more assertive than other WWID & $56.5 \%$ & 26 & $50.0 \%$ & 9 & 0.222 & 0.637 \\
\hline Asks doctor questions about prescriptions & $87.0 \%$ & 40 & $83.3 \%$ & 15 & 0.141 & $0.703^{\mathrm{a}}$ \\
\hline Will not do treatment if disagrees with it & $73.9 \%$ & 34 & $77.8 \%$ & 14 & 0.103 & $1.000^{\mathrm{a}}$ \\
\hline Don't always follow doctor's instructions & $63.0 \%$ & 29 & $61.1 \%$ & 11 & 0.021 & 0.886 \\
\hline \multicolumn{7}{|l|}{ Past experiences and feelings towards healthcare } \\
\hline Feels judged by doctor and doctor's office & $26.1 \%$ & 12 & $27.8 \%$ & 5 & 0.019 & $1.000^{\mathrm{a}}$ \\
\hline Feels that doctors don't want to treat people like them & $23.9 \%$ & 11 & $33.3 \%$ & 6 & 0.589 & $0.533^{\mathrm{a}}$ \\
\hline Experiences positive interactions with doctor office staff & $71.7 \%$ & 33 & $72.2 \%$ & 13 & 0.001 & 0.969 \\
\hline Feels comfortable talking with doctors & $71.7 \%$ & 33 & $72.0 \%$ & 13 & 0.001 & 0.969 \\
\hline Feels doctors listen to them and do not rush them & $65.2 \%$ & 30 & $66.7 \%$ & 12 & 0.012 & 0.913 \\
\hline Experiences ease with obtaining doctor appointment & $45.7 \%$ & 21 & $77.8 \%$ & 14 & 5.388 & $0.020^{*}$ \\
\hline Feels ER is easiest for medical care & $54.3 \%$ & 25 & $88.9 \%$ & 16 & 6.705 & $0.010^{*}$ \\
\hline \multicolumn{7}{|l|}{ Healthcare access } \\
\hline Has health insurance & $84.8 \%$ & 39 & $88.9 \%$ & 16 & 0.181 & $1.000^{\mathrm{a}}$ \\
\hline Distance is a barrier for getting to doctor appointment & $30.4 \%$ & 14 & $33.3 \%$ & 6 & 0.051 & 0.822 \\
\hline \multicolumn{7}{|l|}{ Health information seeking } \\
\hline Actively seeks health information for self & $71.7 \%$ & 33 & $38.9 \%$ & 7 & 5.957 & $0.015^{*}$ \\
\hline \multicolumn{7}{|l|}{ Healthcare setting preferences } \\
\hline Prefers to use ER only or does not use medical care & $28.3 \%$ & 13 & $55.6 \%$ & 10 & 4.187 & $0.041^{*}$ \\
\hline
\end{tabular}

Notes. WWID women who inject drugs, ER emergency room, $X^{2}$ chi-square test

a Statistical significance was calculated using Fisher's exact, two-sided test because at least one cell had an expected count of fewer than 5

${ }^{*} p<.05$

Network, a specialized integrated primary care clinic for justice-involved individuals, about one half of participants were successfully linked to primary care (Morse et al., 2017). Qualitative analyses among a subgroup of program participants indicated that women felt increased empowerment, autonomy, health literacy, and competence to address health conditions (Thomas, Wilson, Bedell, \& Morse, 2019). At another site within the Transitions Clinic Network, researchers found that the provision of specialized primary care services for formerly incarcerated individuals was also associated with lower recidivism rates (Wang et al., 2019). While the Transitions Clinic Network is a national network, Pennsylvania does not have any sites as of March 2021 (Transitions clinic network sites, n.d.).

In a recent trial, patient navigation was associated with a significantly greater percentage of individuals on probation receiving referrals and linkage to primary care compared to control group participants who only received informational booklets (O'Connell et al., 2020). Notably, this pilot by O'Connell et al. (2020) concurrently used a system change intervention which used local change teams to more effectively facilitate linkage to primary care through intersectoral collaborations (e.g., community corrections agencies and officers, clients, and healthcare providers), an approach that has been used to connect justice-involved individuals with HIV testing (Belenko et al., 2017) and substance use disorder treatment (Elkington, Lee, Brooks, Watkins, \& Wasserman, 2020; Howell et al., 2021; Martin et al., 2021; McCarty et al., 2007). Support for these approaches is encouraging (Belenko et al., 2017), but several of these studies are still ongoing (e.g., Howell et al., 2021; Martin et al., 2021). It should also be noted, however, that the syringe exchange that women in this study used also has significant healthcare resources available to participants, yet the difference in preference for healthcare location was still found. Thus, gender-specific outcome data are needed to better understand the mechanisms by which specialized integrated primary care clinics, patient navigation, and systems change interventions could help to address injection drug use and 
justice system stigma, social vulnerability, and the healthcare needs of women who inject drugs on community supervision.

\section{Limitations}

The results of this study should be interpreted with the recognition of several key limitations. For example, injection drug use stigma alone may already account for a significant portion of the variation in the healthcare experiences of women. Over one quarter of respondents felt that doctors judged them and did not want to treat people like them. Small sample size also limits external validity and the possibility of using some types of statistical analyses, and cross-sectional data limits potential for causal inferences. Finally, drug use stigma and the experiences of individuals on community supervision vary regionally, so this sample of Philadelphian women may not generalize to all US adults.

\section{Conclusion}

There is significant underutilization of healthcare in outpatient and clinic-based settings by WWID on community supervision, and initiatives to increase healthcare access have not addressed this gap. To better meet the healthcare needs of WWID on community supervision, it is necessary to look beyond insurance coverage to identify targeted methods of increasing interest in and engagement with outpatient, clinic-based, and community organization-based healthcare providers. More data, particularly gender-specific data, are needed to explore the utility of integrated and intersectoral approaches for addressing the complex healthcare needs and underutilization of outpatient care settings among women who inject drugs on community supervision.

\section{Acknowledgements}

Not applicable.

\section{Authors' contributions \\ $\mathrm{AH}$ wrote the first draft of the manuscript. SB is the principal investigator of the study and conceptualized the study; she also provided supervision and early manuscript draft revisions. PD, JB, and PK developed study materials and surveys, collected participant data, and assisted with conceptualization of study design. All authors have reviewed and approved the final manuscript.}

\section{Funding}

Funding for this study was provided by NIDA, Grant: 1R34DA046305-01. NIDA had no role in the study design, collection, analysis or interpretation of the data, writing the manuscript, or the decision to submit the paper for publication

\section{Availability of data and materials}

The dataset analyzed during the current study is available from the corresponding author on reasonable request.

\section{Declarations}

Ethics approval and consent to participate

The original study for this secondary analysis was reviewed and approved by the Temple University Institutional Review Board, and all participants provided informed consent.

\section{Consent for publication}

Not applicable.

\section{Competing interests}

All authors declare that they have no competing interests.

Received: 10 March 2021 Accepted: 5 April 2021

Published online: 16 April 2021

\section{References}

Bandara, S. N., Huskamp, H. A., Riedel, L. E., McGinty, E. E., Webster, D., Toone, R. E. \& Barry, C. L. (2015). Leveraging the affordable care act to enroll justiceinvolved populations in Medicaid: state and local efforts. Health Affairs, 34(12), 2044-2051. https://doi.org/10.1377/hlthaff.2015.0668.

Belenko, S., Visher, C., Pearson, F., Swan, H., Pich, M., O'Connell, D., ... Willett, J. (2017). Efficacy of structured organizational change intervention on HIV testing in correctional facilities. AIDS Education and Prevention, 29(3), 241-255. https://doi.org/10.1521/aeap.2017.29.3.241.

Biancarelli, D. L., Biello, K. B., Childs, E., Drainoni, M., Salhaney, P., Edeza, A., ... Bazzi, A. R. (2019). Strategies used by people who inject drugs to avoid stigma in healthcare settings. Drug and Alcohol Dependence, 198, 80-86. https://doi.org/10.1016/j.drugalcdep.2019.01.037.

Binswanger, I. A., Whitley, E., Haffey, P. R., Mueller, S. R., \& Min, S. J. (2015). A patient navigation intervention for drug-involved former prison inmates. Substance Abuse, 36(1), 34-41. https://doi.org/10.1080/08897077.2014.932320.

Bohmert, M. N., \& DeMaris, A. (2018). Cumulative disadvantage and the role of transportation in community supervision. Crime \& Delinquency, 64(8), 10331056. https://doi.org/10.1177/0011128716686344.

Brashers, D. E., Haas, S. M., \& Neidig, J. L. (1999). The patient self-advocacy scale: measuring patient involvement in health care decision-making interactions. Health Communication, 11(2), 97-121. https://doi.org/10.1207/s15327027hc11 021 .

Cuellar, A. E., \& Cheema, J. (2012). As roughly 700,000 prisoners are released annually, about half will gain health coverage and care under federal laws. Health Affairs, 31(5), 931-938. https://doi.org/10.1377/hlthaff.2011.0501.

Dion, K., Chiodo, L., Whynott, L., Loftus, B., Alvarez, P., Shanahan, J., ... WilkinsCarmody, D. (2020). Exploration of the unmet health care needs of people who inject drugs. Journal of the American Association of Nurse Practitioners, 32(1), 60-69. https://doi.org/10.1097/JXX.0000000000000201.

Dong, K. R., Must, A., Tang, A. M., Beckwith, C. G., \& Stopka, T. J. (2018). Competing priorities that rival health in adults on probation in Rhode Island: substance use recovery, employment, housing, and food intake. BMC Public Health, 18(1), 1-10. https://doi.org/10.1186/s12889-018-5201-7.

Elkington, K. S., Lee, J., Brooks, C., Watkins, J., \& Wasserman, G. A. (2020). Falling between two systems of care: engaging families, behavioral health and the justice systems to increase uptake of substance use treatment in youth on probation. Journal of Substance Abuse Treatment, 112, 49-59. https://doi.org/1 0.1016/j.jsat.2020.01.008

Fraser, S., Moore, D., Farrugia, A., Edwards, M., \& Madden, A. (2020). Exclusion and hospitality: the subtle dynamics of stigma in healthcare access for people emerging from alcohol and other drug treatment. Sociology of Health \& Illness, 42(8), 1801-1820. https://doi.org/10.1111/1467-9566.13180.

Hawks, L., Wang, E. A., Howell, B., Woolhandler, S., Himmelstein, D. U., Bor, D., \& McCormick, D. (2020). Health status and health care utilization of US adults under probation: 2015-2018. American Journal of Public Health, 110(9), 14111417. https://doi.org/10.2105/A.JPH.2020.305777.

Hien, D., Kropp, F., Wells, E. A., Campbell, A., Hatch-Maillette, M., Hodgkins, C., .. Nunes, E. V. (2020). The "women and trauma" study and its national impact on advancing trauma specific approaches in community substance use treatment and research. Journal of Substance Abuse Treatment, 112, 12-17. https://doi.org/10.1016/j.jsat.2020.02.003.

Howell, B. A., Puglisi, L., Clark, K., Albizu-Garcia, C., Ashkin, E., Booth, T., ... Wang, E. A. (2021). The transitions clinic network: post incarceration addiction treatment, healthcare, and social support (TCN-PATHS): a hybrid type-1 
effectiveness trial of enhanced primary care to improve opioid use disorder treatment outcomes following release from jail. Journal of Substance Abuse Treatment. Advance Online Publication. https://doi.org/10.1016/j.jsat.2021.1 08315.

Kaeble, D., \& Alper, M. (2020). Probation and parole in the United States, 20172018. Bureau of Justice Statistics. https://www.bjs.gov/content/pub/pdf/ppus1 718.pdf. Accessed 31 Mar 2021.

Knapp, C. D., Howell, B. A., Wang, E. A., Shlafer, R. J., Hardeman, R. R., \& Winkelman, T. N. (2019). Health insurance gains after implementation of the affordable care act among individuals recently on probation: USA, 20082016. Journal of General Internal Medicine, 34(7), 1086-1088. https://doi.org/1 0.1007/s11606-019-04900-3.

Levine, D. M., Landon, B. E., \& Linder, J. A. (2019). Quality and experience of outpatient care in the United States for adults with or without primary care. JAMA Internal Medicine, 179(3), 363-372. https://doi.org/10.1001/jama internmed.2018.6716.

Lorvick, J., Comfort, M. L., Krebs, C. P., \& Kral, A. H. (2015). Health service use and social vulnerability in a community-based sample of women on probation and parole, 2011-2013. Health \& Justice, 3(1), 1-6. https://doi.org/10.1186/s4 0352-015-0024-4.

Martin, R. A., Stein, L. A. R., Rohsenow, D. J., Belenko, S., Hurley, L. E., Clarke, J. G., \& Brinkley-Rubinstein, L. (2021). Using implementation interventions and peer recovery support to improve opioid treatment outcomes in community supervision: protocol. Journal of Substance Abuse Treatment. Advance Online Publication. https://doi.org/10.1016/j.jsat.2021.108364.

McCarty, D., Gustafson, D. H., Wisdom, J. P., Ford, J., Choi, D., Molfenter, T., ... Cotter, F. (2007). The network for the improvement of addiction treatment (NIATx): enhancing access and retention. Drug and Alcohol Dependence, 88(23), 138-145. https://doi.org/10.1016/j.drugalcdep.2006.10.009.

McCormack, L., Thomas, V., Lewis, M. A., \& Rudd, R. (2017). Improving low health literacy and patient engagement: a social ecological approach. Patient Education and Counseling, 100(1), 8-13. https://doi.org/10.1016/j.pec.2016.07. 007.

Mehta, K., Hoadley, A., Ray, L. A., Kiluk, B. D., Carroll, K. M., \& Magill, M. (2021). Cognitive-behavioral interventions targeting alcohol or other drug use and co-occurring mental health disorders: a meta-analysis. Alcohol and Alcoholism. Advance Online Publication. https:/doi.org/10.1093/alcalc/agab01 6.

Morse, D. S., Wilson, J. L., McMahon, J. M., Dozier, A. M., Quiroz, A., \& Cerulli, C. (2017). Does a primary health clinic for formerly incarcerated women increase linkage to care? Women's Health Issues, 27(4), 499-508. https://doi. org/10.1016/j.whi.2017.02.003

O'Connell, D. J., Visher, C. A., \& Becker, P. (2020). Linking individuals on probation to health care: a pilot randomized trial. Health \& Justice, 8(1), 1-7. https://doi. org/10.1186/s40352-020-00110-w.

Pizzicato, L. N., Drake, R., Domer-Shank, R., Johnson, C. C., \& Viner, K. M. (2018). Beyond the walls: risk factors for overdose mortality following release from the Philadelphia Department of Prisons. Drug and Alcohol Dependence, 189, 108-115. https://doi.org/10.1016/j.drugalcdep.2018.04.034.

Pourat, N., Davis, A. C., Chen, X., Vrungos, S., \& Kominski, G. F. (2015). In California, primary care continuity was associated with reduced emergency department use and fewer hospitalizations. Health Affairs, 34(7), 1113-1120. https://doi. org/10.1377/hlthaff.2014.1165.

Salem, B. E., Nyamathi, A., Idemundia, F., Slaughter, R., \& Ames, M. (2013). At a crossroads: reentry challenges and healthcare needs among homeless female ex-offenders. Journal of Forensic Nursing, 9(1), 14-22. https://doi.org/1 0.1097/JFN.0b013e31827a1e9d.

Saloner, B., Bandara, S. N., McGinty, E. E., \& Barry, C. L. (2016). Justice-involved adults with substance use disorders: coverage increased but rates of treatment did not in 2014. Health Affairs, 35(6), 1058-1066. https://doi.org/1 0.1377/hlthaff.2016.0005.

Saluja, S., McCormick, D., Cousineau, M. R., Morrison, J., Shue, L., Joyner, K., \& Hochman, M. (2019). Barriers to primary care after the affordable care act: a qualitative study of Los Angeles safety-net patients' experiences. Health Equity, 3(1), 423-430. https://doi.org/10.1089/heq.2019.0056.

Thomas, K., Wilson, J. L., Bedell, P., \& Morse, D. S. (2019). "They didn't give up on me": A women's transitions clinic from the perspective of re-entering women. Addiction Science \& Clinical Practice, 14(1), 12. https://doi.org/10.1186/ s13722-019-0142-8.

Thomas, K. C., Owino, H., Ansari, S., Adams, L., Cyr, J. M., Gaynes, B. N., \& Glickman, S. W. (2018). Patient-centered values and experiences with emergency department and mental health crisis care. Administration and Policy in Mental Health and Mental Health Services Research, 45(4), 611-622. https://doi.org/1 0.1007/s10488-018-0849-y.

Transitions clinic network sites. (n.d.). Transitions clinic. https://transitionsclinic. org/locations/ Accessed 31 Mar 2021.

van Olphen, J., Eliason, M. J., Freudenberg, N., \& Barnes, M. (2009). Nowhere to go: how stigma limits the options of female drug users after release from jail. Substance Abuse Treatment, Prevention, and Policy, 4(1), 1-10. https://doi.org/1 0.1186/1747-597X-4-10.

Wang, E. A., Lin, H. J., Aminawung, J. A., Busch, S. H., Gallagher, C., Maurer, K., .. Frisman, L. (2019). Propensity-matched study of enhanced primary care on contact with the criminal justice system among individuals recently released from prison to New Haven. BMJ Open, 9(5), e028097. https://doi.org/10.1136/ bmjopen-2018-028097.

Zlotnick, C., Najavits, L. M., Rohsenow, D. J., \& Johnson, D. M. (2003). A cognitivebehavioral treatment for incarcerated women with substance abuse disorder and posttraumatic stress disorder: finding from a pilot study. Journal of Substance Abuse Treatment, 25(2), 99-105. https://doi.org/10.1016/50740-5472 (03)00106-5.

\section{Publisher's Note}

Springer Nature remains neutral with regard to jurisdictional claims in published maps and institutional affiliations.
Ready to submit your research? Choose BMC and benefit from:

- fast, convenient online submission

- thorough peer review by experienced researchers in your field

- rapid publication on acceptance

- support for research data, including large and complex data types

- gold Open Access which fosters wider collaboration and increased citations

- maximum visibility for your research: over $100 \mathrm{M}$ website views per year

At BMC, research is always in progress.

Learn more biomedcentral.com/submissions 